\title{
Exploring school principals' responses to the needs of Somali immigrant students
}

\author{
Shukri Nur \\ Independent Scholar \\ shnur42@yahoo.com \\ Mohamed A. Nur-Awaleh \\ Illinois State University \\ manuraw@ilstu.edu
}

\begin{abstract}
This paper explored school principals' responses in addressing the perceived educational needs of Somali immigrant/refugee students; and explored how school principals might seek to create culturally responsive and inclusive schools that build a partnership with Somali families. This qualitative exploratory study combined aspects of convenience and purposeful sampling to learn about how the school principals addressed the needs of the Somali immigrant students; and the extent to which they sought to create inclusive schools and build partnerships with the Somali families. We conducted interviews with a total of three school principals in three different schools who served these students and their families. This study shows that in the initial contact with Somali students, the school principals had very little awareness and experience in dealing with Somali refugee and immigrant students who continue to face challenges in adjusting into their schools. To address the educational needs of Somali students requires an approach that transcends the provision of ESL classes. It also requires a transformative leadership approach that advocates for the needs of both the students and the parents and seeks to establish multicultural and mentoring programs which could play a role in better meeting the educational needs of all students.
\end{abstract}

\section{Introduction}

Recently arrived Somali immigrant high school students face the challenge of adjusting to schools in the United States (Perkins, 2000). American schools have not been prepared for the large influx of Somali students. From 1991 until the present, hundreds of newly arrived students have enrolled in public schools in various cities, including Minneapolis/St. Paul, Minnesota, Columbus, Ohio, and small towns in Wisconsin. Apart from English language classes, schools lack programs that are appropriate for refugee students, whose language and culture differ from those of the mainstream American culture (Zehr, 2001).

To comprehend the experiences of Somali refugee and immigrant students within American public schools, first it is important comprehend the socioeconomic, cultural, and political context in which the Somali community is situated. Somalis in the United States have settled in urban cities, where the families encounter cultural challenges, language barriers, racism, and social and economic inequalities (Darboe 2003; Farid \& McMahan, 2004). For 
instance, housing is one challenge that newly arrived Somalis often encounter; because of their low levels of education and income, Somali families are marginalized and segregated into lowincome housing, which is not safe from social problems unique to urban cities, such gang violence (Darboe, 2003; Farid \& McMahan, 2004). In addition to this housing problem, most recently arrived Somalis face English language barriers, which hinder their possibility of obtaining meaningful jobs.

With respect to the experiences of Somali students and parents with the school system, parents and their children continue to face challenges caused by cultural and communication barriers. For instance, the most difficult issue for school leaders and educators in terms of working with Somali refugees and immigrants is their disrupted education caused by the civil war (Forman, 2001; Schultz \& Hertz, 2006). Some of the children have grown up in refugee camps in Kenya and have never attended school in the 18-year duration of the civil war.

In this paper, we explore the approach of school principals in serving the Somali parents and children. How best might school principals respond to the needs of immigrant and diverse students in general and Somali students in particular. However, if school principals are facing the problem of how best to respond to the needs of Somali immigrant students, then they would do well to consult the existing research for the inclusion of ESL students, students suffering from emotional problems and students from poverty which might interfere with the education of the individual and the educational environment. If school principals and educators first build a relationship with the Somali families and try to understand their lived experiences, then will they be able to provide adequate education that meets the educational needs of the children and their parents?

\section{Purpose of the study}

The objective of this study is twofold:

(1) To examine school principals' responses in addressing the perceived educational needs of Somali immigrant/refugee students, and

(2) To explore how school principals might seek to create culturally inclusive schools that builds a partnership with Somali families.

\section{Research questions}

(1) What have been school principals' approaches/responses to addressing the educational needs of Somali immigrant students?

(2) To what extent do school principals build culturally inclusive school environments that connect and promote partnerships between the Somali families and the schools?

(3) The literature review question is: what does research show about school leadership responses to educating immigrant students?

\section{Significance of the study}

The importance of this study is that there is a gap in the literature on school leadership and Somali immigrant students. In other words, research on both Somali and immigrant students is minimal. In fact, according to Riehl (2000), there is inadequate research which carefully explores school administrators and immigrant students in general. Also, this study will contribute to literature on school leaders' roles in addressing the educational needs of Somali immigrant 
students in particular and secondarily other immigrant students in general. Furthermore, this study could be useful to practitioner and other researchers that seek to research on school principals and immigrant/refugee student studies.

\section{Methodology}

\section{Participants of the study}

In this study, a total of three school principals were interviewed. The ethnicity of the three principals is Caucasian. Two of the school principals are female and the third participant is a male. Pseudonyms were used for both the participants and the schools. Lisa Anderson is the principal of North Albion Junior High, (seventh-ninth grade). The total number of students is 800. At North Albion, $70 \%$ of the students are Caucasian, $27 \%$ of are students of color including: African-Americans, Hispanic and Somali, with the majority being Somalis. Also, 10\% are ESL students, mostly new immigrant students (20\% Latino, 25\% Somali and 5\% Asian). Anderson has been the principal of North Albion for 10 years, her total time as a principal is 30 years. Education degrees include: Masters in Educational Administration, Doctorate in Educational Leadership, Bachelor in Teacher Education, Mathematics and Social Studies.

Tom Baldwin, is the principal of Hadrawi Elementary Charter School (K-fourth grade) in Minneapolis, Minnesota. The student population is 1200 with an ethnicity of $80 \%$ Somali, $10 \%$ Oromo (Ethiopia), and the other $10 \%$ are students of Middle Eastern origin. Baldwin has been a principal at Hadrawi Elementary for 2 years. He was previously the superintendent of a large district for a number of years. Baldwin's level of education include: Doctorate in Educational Administration, Master of Science in Special Education and Bachelor in Teacher Education.

Nancy Smith is the school principal of Mandela Elementary School in St. Paul, Minnesota. Smith has been principal at Mandela for 10 years. Her qualifications include, Advanced Certificate in Educational Administration, Master of Educational Administration and Bachelor in Teacher Education. Student demographics include: 68\% of the African American, with a majority Somali born, and (Somali students are included in the African-American category); $20 \%$ are Hmong students, $5 \%$ Latino and 7\% Caucasian.

\section{Data collection}

This qualitative study combined aspects of convenience and purposeful sampling. It was a convenience sample because the participants (school principals) were chosen from one geographical area of St. Paul/Minneapolis and a Suburb of Minneapolis. The sample was also purposeful since personal networks were used in order to identify two to three school principals that were dealing with relatively large Somali immigrant student populations. The criteria for selecting the school principals included the number of years the principals had been dealing with Somali immigrant students, with two years being the minimum period required by the principal to be an administrator in the schools chosen for the sample.

To learn about how the school principals addressed the needs of the Somali immigrant students; and the extent to which they sought to create inclusive schools and build partnerships with the Somali families. We conducted interviews with a sampling of two elementary and one middle school principals from St. Paul/Minneapolis and a suburb of Minneapolis. With the interviewees' permission, the interviews were audiotaped and then transcribed. We conducted one semi-structured interview for the duration of approximately one hour with each of the participants. Semi-structured interviews provided me with the opportunity to probe and ask a 
follow-up question. A total of eleven questions were asked the participants. Some parts of the questions focused on the challenges the principals faced in dealing with Somali immigrant students and families whose values, culture and language were different from those of the administrators. The other questions were designed to solicit how the school principals addressed the needs of Somali immigrant students and also whether they created inclusive schools that established partnerships with the families.

Once data were collected through interviews, we analyzed them to address the two research questions. We used theme analysis, a process through which themes are identified, highlighted and compared within the findings of the research (Berg, 2004). Since, this was a small-scale study, rather than using a software program that could have assisted me with data coding, management, and analysis (e.g., Atlas/ti, Nud*ist), we manually created codes to label the findings. For instance, after we transcribed the interviews, we read and reread the transcriptions, identifying themes with codes. We then retrieved text segments and placed the data in categories under the relevant codes. This iterative labeling-and-identification process made the theme analysis easier. The codes we used to label the findings include "challenges," "addressing the needs of immigrant students," "culturally inclusive" and "school/family partnership."

\section{Limitations of the study}

This study is limited to only three schools located in one urban city in a state in the Midwest. The limitation of this study is that it is a small sample that will focus on one geographical area; therefore, the findings of the study may not be generalizable to other geographical areas. Despite this limitation, there is much to be learned from this study, which will explore the approaches of school principals toward working with Somali immigrant students.

\section{Overview of the literature}

The literature review for this study is drawn from a variety of literature including the immigrant and refugee literature, culturally inclusive environment and transformative leadership. The literature on school leadership and immigrant students shows that school administrators who lacked an understanding of diversity, student cultures and backgrounds focused more on maintaining school structures and employed the deficit model. That is, more emphasis was put on student behavior than addressing the educational needs of immigrant students and assisting the students to adjust into the school (Gardiner \& Enomoto, 2006; Gitlin, Buendia, Grosland \& Doumbia, 2003).

The literature indicates that to address the needs of refugee and immigrant students in our schools, it is important first to understand the various backgrounds of these students. Immigrant and refugee students have certain characteristics that must be recognized and understood if school leaders are to educate this population effectively. Research that focuses on refugee and immigrant students has revealed that to educate immigrant and refugee students, attention to their psychological and social needs is first required (Rutter, 2001). For instance, many immigrant children who are attending American schools are from war-torn developing countries. According to Machel (2001), "War undermines the very foundation of children's lives, destroying their homes, splintering their communities and shattering their trust in adults" (p. 80). In addition, 
refugee children who were exposed to the traumas of war have often witnessed violence or killings and have experienced prolonged stays in refugee camps (Bateman, 1993).

Settling in and adapting to North America and Europe has not been an easy task for the refugees and immigrants. These new immigrants often encounter numerous challenges, including economic, social, and acculturation ones (Portes \& Zhou, 1993; Zhou, 1997). For example, Portes and Zhou (1993) note that immigrants often experience poor socioeconomic conditions in the host country. Because of the language barrier, an inadequate education, and a lack of appropriate skills required for the job market, immigrants are often trapped in the lowest paying jobs, ones that continue to exploit them, further marginalize them, and place them at the bottom of the economic ladder. Many Somali immigrants and refugees fit into Portes and Zhou's (1993) description of immigrants in the United States. For instance, some of the recently arrived Somali parents with children not only face the challenge of the English language barrier, but also illiteracy in the Somali language. Being impoverished and with a low level of education, Somali immigrants work in low-paying jobs in major cities such as Minneapolis/St. Paul, Minnesota, and Columbus, Ohio. In search of jobs and a lower cost of living, Somalis have also settled in smaller cities such as Rochester and St, Cloud, Minnesota, and Barron, Wisconsin; most of these immigrants in small towns work in poultry and meat-packing factories (Schaid \& Grossman, 2003).

Moreover, the harsh socioeconomic conditions in which immigrants live are not limited to low-skilled jobs, but also include high unemployment compared with the American population. Prior to the economic downturn of 2009, Bender and Murphy (2009) reported that Somali immigrant and refugees in the United States experience a high unemployment rate, approximately $17 \%$, which is twice the national average. Indeed, the lack of resources and jobs limits the prospect of families advancing up the economic ladder and integrating into society easily. This also traps families in a cycle of poverty, which in turn makes the upward mobility of the family difficult by restricting their choices, such as the ability to live in safe neighborhoods and enroll their children in good schools.

Furthermore, as various studies have reported (Portes \& Zhou, 1993; Zhou, 1997), immigrants are often concentrated in inner cities or low-income neighborhoods. Cedar-Riverside, one of the neighborhoods in Minneapolis where Somalis are concentrated, is known as a highcrime area, where Somali boys, having limited choices, turn to gangs and violence. In CedarRiverside near Minneapolis, Somalis are concentrated into low-income high-rise towers, where thousands of Somalis immigrants reside. The neighborhood is known for its crime and gang violence by Somali boys. It is reported that Somali gang members make up $1 \%$ of the gangs in Minnesota (Yuen, 2009). Most of these young men involved in gangs are dropouts from school, who adapt to hip-hop culture and resort to gang life and criminal activities.

While adapting to the norms and ways of life of the host country, immigrant families also experience various cultural stressors imposed on them by their new country. Almost every immigrant family experiences "acculturation stress," which involves adapting to the cultural norms of the new country into which they have settled. Other challenges they face include gender role conflicts within the family (parents), language barriers in the new country, and economic hardships (Alitolppa-Niitamo, 2002). For instance, in Somali culture, the father is the breadwinner; however, because of the lack of skills required for jobs in the United States, the high unemployment experienced by Somali men places stressors on the family when men are not able to secure employment and thereby provide for their families. Thus, the father feels inadequate for not being able to provide for the family. This causes disintegration of the family 
structure and often divorce. As a result, the cohesion of the family unit is affected by these stressors from the new environment.

Somali families are prime examples of immigrants who are experiencing acculturation stress, which has contributed to the disintegration of some immigrant families. Zhou (1997) showed that the success of the immigrant family in the new country depends on the "social capital" of the family, which is family cohesion (p. 993). In other words, without a solid family that is socially grounded in its spirituality and values, it is overwhelmingly difficult for parents to adequately support and educate their children. Even in the cases of solid families with social and spiritual grounding, the potency of the family is greatly diminished by the onslaught of acculturation stress.

Gardiner and Enomoto (2006) conducted a study that examined six urban school principals' leadership role as multicultural administrators. The research shows that some the school principals' responses to meeting the educational needs of diverse students involved the deficit thinking model. For instance, one administrator's perspective on educating immigrant students, demonstrates as he put it: "We have some students out of Africa right now that have basically been raised in a tent camp and don't know how to flush a toilet, how to go through a cafeteria line. Our goal is to socialize (the students) to our educational system, as well as teach them some English basic skills" (Gardiner \& Enomoto, 2006, p. 570). Children from the refugee camps may not know how to flush a toilet; however, the administrator did not explain what he is doing to help the refugee children to adjust into the new school environment. Instead of focusing on the children not being able to flush the toilet, the discussion should have focused more on ways to support the children and include them. As such, from the administrator's comments, there seems to be lack of awareness of the gravity of the damage that refugee camps do to refugee children. In other words, the administrator's insensitive and culturally fraught commentary did nothing to empathize with the students and address the problem.

\section{The Importance of transformative leadership for refugee and immigrant students}

This part of the paper focuses on the role transformative leadership could play in order to foster schools that are culturally inclusive. Shields (2003) replacing Leithwood's transformational leadership style includes the creation of new cultures that are just, caring, democratic, and optimistic. Transformative cross-cultural leaders understand the diverse cultural context in which they operate and promote the creation of a culture that takes into account the changing populations of the school or district (Shields, 2003). The transformative cross-cultural leader must always be conscientious of the feelings and perceptions of others.

Also, Shields (2003) inform us that the cross-cultural transformative leader must model an ethical decision-making process and set the standard for all within the community of difference. As part of the decision-making process, leaders and teachers must continuously ask themselves, before carrying out an action, (1) who benefits; who is disadvantaged, (2) who is included; who is excluded, (3) who is privileged; who is marginalized, (4) who is legitimated: who is devalued, (5) to whom are we listening; who are we not hearing, and (6) what data are we using for our decision making (Shields, 2003, p. 81). Additionally, to meet the educational needs of diverse students requires educational transformative leaders to foster democratic schools and classrooms. To do so, educational leaders would incorporate social justice. As Furman and Shields (2005) put it: "Leadership for social justice requires a careful examination of one's own 
beliefs and practices and those of the institution within which one works, for justice is played out in both individual relationships and systemically, in policies that assume that any single approach to curriculum, programming, resource allocations, or accountability is appropriate for children..." (p. 126). Indeed, for school leaders to have the potency to adequately address the diverse needs of immigrant and other students of diversity requires them also to operate from a moral purpose which seeks to promote collective interest of the school and the community.

Scholars who discuss equity have promoted the values of transformative leadership. They have shown that school principals not only must examine how equitable their schools are (Skrla, Scheurich, Garcia, \& Nolly, 2004), but also may have an outsider or "critical friend" who advocates for social justice in the schools. Indeed, equity audits might also help school principals become aware of their stance as well as the values, attitudes, and practices that are ingrained in the school and that may have led to impediments to an equitable education for students (Skrla et al., 2004). For instance, schools that have refugee and immigrant high school populations might establish equitable access to enrichment and extracurricular, gifted, and preuniversity courses. The authors recommend that refugee students be placed into those programs to enhance the equity of the programs and to create learning experiences for them (Harklau, 2008). Teaching refugee and immigrant students the sociocultural expectations, and providing them with the tools to prepare for college are also important ways of attending to the needs of these students (Walqui, 2008).

Furthermore, the literature consistently recommends that to address the needs of refugee students, school principals ought to end the "one size fits all" approach to educating children and change their schools into learning communities that attend to the diverse needs of the students. Hence, in creating a successful learning environment for refugee and immigrant children, leaders might (1) challenge teachers' deficit thinking through conversations and professional development, and thereby alter their attitudes; (2) include the diverse needs of the children in the school's vision and goals, and communicate the message that it is the responsibility of educators in the entire school and community to educate refugee and immigrant students; and (3) create a belief that refugee and immigrant students can be successful in rigorous classes, instead of tracking children into lower tracked classes, and thereby eradicate segregated programs and create heterogeneous grouping (Coady et al., 2008; \& Dwyer, 1998). In fact, these recommendations appear to be embedded in the social justice values that are also intertwined with transformative leadership.

\section{Major findings and discussion}

To understand the school principals' approaches and the process of addressing Somali immigrant/ refugee educational needs, we asked the school principals about the challenges they have encountered when dealing with the Somali immigrant students. All of the school principals reported that the English language barrier was a major challenge for the students and that the students primarily struggled with reading and writing. For instance, Smith stated that she had to create a language academy in each grade from first to the fourth grade levels. The findings show that all the school principals interviewed reported that they emphasized improving language proficiency for the students.

Another challenge the school leaders had to confront was the cultural barrier and lack of understanding and dialogue on the part of the schools and the Somali parents. Anderson indicated, "The initial contact with the Somali kids was difficult because they didn't have anyone 
to talk to with. They didn't have anyone in their own language to explain to them this is how it works at a public school in United States." Anderson seemed to imply that because of the language barrier, the students may not have had a good understanding of the expectations, the values and the code of conduct to which the entire school adhered.

Furthermore, Anderson reported that lack of communication between the parents, teachers and students contributed to the hostility between the parents and the teachers. As such, she described the relationship between the school and the Somali parents as "very adversarial." Anderson indicated that the Somali boys were suspended frequently because they engaged in fighting more often than their classmates. The problem was aggravated by the unavailability of Somali interpreters to the parents and the school. She stated that there was anger on the part of the Somali parents and they did not understand on what grounds the school kept on suspending their kids from school. The boys would also get angry and be defiant towards the teachers. The teachers on the other hand felt that the kids had to be suspended because they broke the rules by fighting. It is evident from Anderson's account of how the students were dealt with, that there appears to be cultural dissonance and a lack of understanding on the part of the school of the students' refugee experience. It is also clear from Anderson's statements there was frustration on the part of the school principal and the teachers, and this may have been the result of lack of awareness of the experiences that the Somali children were experiencing in adjusting to American schools. Research shows that immigrant children that have witnessed civil wars experienced psychological stress and traumas not only during the war but also while being in the refugee camps. This causes the children to be distrustful and fearful of people in authority. It could also be that the children were from the refugee camps not used to school and structure, and being defiant and resisting authority may have been adaptive defense mechanisms (McBrien, 2005).

Anderson asserted that the relationship between the school and the Somali parents somewhat began to improve when a Somali community advocate, Layla Hassan intervened and began providing an interpreter to the parents and the teachers. But the school principal also reflected on her approach with the students by reevaluating her perspective and teachers' attitudes towards the Somali boys. For instance, she contended,

I have to say with pride, that our school I think just stepped back a little bit and said, you know what we need to do! We need to be more patient. We need to figure out why these kids are acting as they do. And we need to provide some support to them so that they don't feel they need to be sort of the tough guy. Over a period of like maybe a year or two years, we worked with the teachers to make them more aware of the situation.

North Albion School demonstrates a classic example of lack of preparedness of school principals in addressing the diversity issue. In other words, Anderson's school depicts a suburban middle school that struggles with immigrant students that have cultures and languages different than the dominant middle class Anglo-Saxon culture in the suburban area.

Another challenge two of the three school principals interviewed indicated they had to confront was involving the Somali parents in the school. For instance, Anderson and Smith reported that they had to embark upon reducing the disconnection between the Somali parents and their schools. They attested that the Somali educational assistants made an enormous impact on bridging the communication gap between the parents and the teachers. Smith indicated that she hired Somali interpreters who made it possible for the parents to be able to communicate 
with the teachers. Also she stated that she invited a Somali community organization leader who gave workshops to the teachers about Somali culture.

\section{School principals' strategies of promoting the educational needs of Somali immigrant refugee/immigrant students}

The analysis from the interview data also shows that in North Albion and Mandela Elementary School, one of the ways the school principals addressed the educational needs of Somali immigrant students was first overcoming the cultural barriers and lack of communication among stakeholders of the school. In other words, according to Anderson and Smith, once the schools and the Somali parents were on the same level of understanding, then it became possible to focus on the academics.

Furthermore, all of three principals that were interviewed, Anderson, Smith and Baldwin identified improving the English language as responding to the Somali students' educational needs. Thus, emphasis on students' language acquisition was given a priority. For example, Baldwin explained his approach to addressing the educational needs of Somali immigrant students; he pointed out that his approach to improving English language proficiency for the Somali students involves a very detailed process in which they incorporate English as a second language into the teaching of other subjects. Baldwin explained,

We have three specialized ESL teachers and we use a model called SAIF sheltered instruction model. We are sending our special ESL teachers to training, and then we do ongoing training with all staff on weekly bases. So we do weekly training English as a second language. We are school of $97 \%$ of students are ESL students. So we are focused on every classroom teacher being the person that has to maintain a plan and a focus on accomplishing language proficiency standards in the classroom.

The principals were asked specific programs they designed for the Somali immigrant and refugee students. For instance, the after school tutoring program is a district program that is offered in North Albion and the two schools. However, Anderson indicated that the Support Group program, which was created by Mubarak, is unique to her school. The program provides Somali ESL students the opportunity to have a conversation about the issues and the difficulties they have with the school. Anderson described the program as she put it: "The only thing, that I would say we do differently are the opportunity for kids to have someone from Somalia here, and Mubarak actually started to provide what we call a support group. So once or twice a week, she would meet with the boys and then on a different day talk with the girls and just find out how they are feeling about school and how things are going?" Anderson exhibits an understanding of the importance of providing immigrant students a space for conversation where the students are able to voice their concerns. As well, Hussein and Mubarak were also reported to provide support to the Somali ESL students and the teachers. They would do tutoring as they were able to give some directions in Somali language and then help the students figure it out in English. Moreover, Anderson indicated that she established a grade eight and nine honors program, in which students of color including the Somalis are identified for a gifted program designed for minority students. Students that are placed in the program are kids who have as Anderson described,

What we call a promise! They have promised to be good leaders, strong students...they have promised to take the advanced placement classes at the high school and to go to college. Many students in the United States that are in what we call the gifted and 
talented classes, the kids of color or the immigrants not included in those programs because usually it is just by test scores. But four years ago... and now this year too, we have had out of 20 kids that are in the program, we have had anywhere from 2-6 Somali kids in the program, they have just blossomed, especially the girls.

Thus, by facilitating the program and enhancing the number of Somali and other minority students in the gifted program, Anderson demonstrated an awareness of the equity concerns associated with gifted programs by including more culturally and linguistically diverse students in the gifted program.

At the Mandela school, Smith on the other hand pointed out that one of the ways she responded to the needs of Somali immigrant students was by creating programs for both the Somali ESL students and their parents. Programs that include: language academy at each grade level and the SALT program which is an afterschool program. The SALT program focuses on teaching the Somali language to the children. According to Smith, a Somali teacher and educational assistant teach the students every day after-school. Smith discussed that the Somali parents requested for the SALT program. She said, "I think partly was they [parents] didn't want their children to forget their language. And if they were younger children, they may not be even known about reading and writing Somali, this is teaching them that. Because many of the families want their culture to be retained, and so this is one way we could do that." Smith's approach to addressing the educational needs of Somali students involved providing educational services that were needed by the Somali parents and the community. As such, Smith appeared to be empathetic and thereby more receptive to the desires of the Somali parents to maintain their identity and language.

Moreover, for Smith, providing Somali language classes to the students is way of promoting a culturally inclusive school where the diverse cultures of Somali, Hmong and other cultures are equally valued. This is evident from her remarks in which she commented, "I think it is pretty inclusive of everybody, and then constantly changing. Our school has the highest Somali population of all the schools in the district. I think we have a lot more Somali programs here then other schools would have." In addition, Smith's philosophy of educating the ESL students encompassed educating the parents by proving English language classes. She indicated that there are two ESL classes offered during the regular school hours. She explained the benefits of the program to the families, "The Somali parents are learning English, as well as how to apply a job, careers, interviews and becoming a citizen. Right now this year, we have 50 parents of Somali background that are in that class." Smith seemed to use a holistic approach to addressing the needs Somali immigrant students which also involved inviting the parents into the school and proving certain programs that were vital for both of the parents and children.

The school principals were asked about their perspectives on other ways that would have been more successful to address the educational needs of Somali immigrant/refugee students. Anderson stated that she prefers the Newcomer program- specifically designed for ESL immigrant students. She expressed her preference of the Newcomer program, which is very structured and emphasizes more in-depth on teaching English language and math. She indicated that the Newcomers program would have been more appropriate for immigrant students because they would have received six hours of ESL and math instruction, as opposed to three hours of ESL English, which mainly focuses reading and math in her school. In the other three hours ESL students in her school take elective courses that include art and music. She claimed that based on her previous experience of working with other school districts that had the Newcomer program; 
students that spent 6 hours a day in the Newcomer program developed the beginning language skills and reached a level of conversational English where they are able to understand instruction.

On the contrary, school Principal Baldwin, declared that he found heterogeneous grouping to be a better way of educating the ESL students. He was against homogeneous grouping of ESL students, and noted that it has the tendency to abandon children permanently in one group. He explained that the kids are grouped and then regrouped so that the group is constantly changing, and students are integrated with regular students. He elucidated by saying,

We do heterogeneous grouping ... with regard to language. We also do that with our reading program, SIAF reading program which is a national program...The heterogeneous grouping is based on where children are at with understanding reading. Math, we do less grouping in the math... But the type of grouping that we would do is math concepts, we are teaching math concepts... a Somali educational assistant may take three kids in the back of the classroom and work with the three kids and put them right back in without taking them out of the classroom.

On the other hand, Smith mentioned that she promoted dialogue between the students and the teachers - which she claimed has enormously reduced the discipline problems in her school. She illustrated, our school has 'Responsive Classroom Building.' It is a way of teaching children that we are a community of caring learners for each other. We start out with morning meetings and everyone is in a circle and they talk about various things. They may talk about things that happened in the community or things that happened the evening before or maybe news articles that people are aware off, it depends on the level of the children. But all the classes have the morning meetings, and what that does is it helps some children if they had difficulty in the home, or even on the bus to be able to resolve that through the class meeting before it becomes an issue. Smith reported that Responsive Classroom Building helped her students to adjust to school, and at the same time provided the entire school the opportunity to have informal conversations and interactions.

\section{Culturally inclusive and partnership between the schools and Somali immigrant families}

This section of the paper will focus on the extent to which school principals seek to build partnership with the Somali parents and create culturally inclusive schools. With respect to creating culturally inclusive schools that encourages the Somali families to be part of the school community, two of the three school principals interviewed, Anderson and Smith indicated that they focused on first building a trust and relationship with the Somali immigrant parents. They alluded to creating spaces for a dialogue and understanding. Anderson indicated that she understands the social and economic conditions of the families - that some parents are not able to attend parent teachers' conference because of work schedules. Therefore to foster partnership with the parents, she said, "In the fall, we do conferences at a couple of apartment buildings that had the most Somali families, so that they don't have to drive some place... So we do a little outreach to them because we want them to know that they are important. So in the fall, we hold conferences where they live. It is very comforting because they can talk to someone in their own language. There is just a trust that has been built up in our school." Smith also expressed an awareness of the Somali culture and Islam which had enabled her to understand better the needs and experiences of the Somali students and their parents. As well, Smith's definition of culturally inclusive school meant creating a school community in which the Somali families felt a sense of 
being part of the school community. For instance, the Somali families utilized the gym in the school for the night prayers during the month of Ramadan. She also provided a quiet place for some sixth grade students that desired to pray during the lunch hour. For Smith providing certain services that are needed by the Somali families enabled her to build partnership with the Somali families. In addition, Smith pointed out that she works closely with a Somali community leader, who represents the families in the neighborhood. The community leader discussed the needs and concerns with Smith.

When we asked whether teachers are culturally knowledgeable in dealing with the Somali immigrant students, the findings show that at North Albion, the teachers are reported to have multicultural education training; also, the principal and the teachers read articles and books and engage in discussions on certain issues that include poverty, change, the achievement-gap and the possible reasons students of color are behind. However, Anderson voiced that the curriculum represents the values of the Caucasian middle class. Indeed, Anderson did not show how she would attempt to promote a culturally diverse teachers and curriculum. She left that task to the school district because she said the school follows state curriculum. Creating inclusive school requires from school principals to foster respect for cultural diversity. It is vital that the curriculum reflects the cultures and histories of the immigrant children so that the children and their families are more connected to the schools.

At Mandela school, Smith maintained that the teachers in her school understand students' cultural backgrounds that it was a process that involved learning for her and the teachers. She explained, "Overtime it has evolved that way. When I go back and think about the first families that came, we had to have that awareness of the culture." However, Smith acknowledges that she would still like to see more culturally diverse teachers and educational assistants. She said that the obstacle to establishing more diverse faculty is a lack of Somali teachers and educational assistants.

This study also shows that the partnership between the school and the Somali families at North Albion is not strong. Indeed, both Anderson and Baldwin also explained the challenges that the Somali immigrant families are going through. Thus, the findings show that in the initial contact with the Somali families, the school principals were unaware of the lived experiences of the Somali and other refugees' children. For Anderson, for instance there was an expressed lack of awareness of the experiences of the Somali and Hmong children. She explained,

Certainly, one of the things I was lacking was just my understanding of what their lives were like in their homeland, what their educational experiences were like in their homeland. Certainly, for the Hmong and for the Somali students I was unaware of how much violence the children saw and how much of an impact it had on them. For some of the kids, no avenue to really talk about some of the deaths they saw. Just that whole general knowledge, understanding sensitivity to what they experienced before they came here is probably the area that I was lacking the most in.

Anderson did not discuss about how she would address the students that have been exposed to violence.

Both Anderson and Smith showed that, in the beginning, they faced numerous challenges in dealing with the Somali immigrant students. More specifically, Anderson's school expected the students to behave and learn like the native-born students. That lack of awareness of the lived experiences of the kids contributed to misunderstandings on the part of Anderson and her teachers. 
To adequately address the educational needs of immigrants and other culturally and linguistically diverse students - and to eventually eliminate the ever-persistent achievement gap - transformative leadership theory provides school leaders a framework that can help them address equity, diversity and democracy, and can ultimately bring change into the schools. In other words, to create school community that is suitable for educating ethnically and linguistically diverse students, schools must strive to become what Shields (2003) refers to as "communities of difference." She describes such communities as

communities in which we value and respect one another as we learn how to live and work together. These schools are communities in which all students, regardless of home situations or backgrounds, are expected to learn and are helped to achieve high standards. They are communities in which difference is neither feared nor excluded but included, understood, and respected. (p. xii)

In terms of changing the schools and turning them into democratic schools that celebrate diversity, Anderson has a long way to go in turning the school into "a community of difference" and connecting the school to the immigrant community. She indicated that she has just "opened the door" to hear the voices of the Somali immigrant parents and would like them to be involved in the school and site council. Also, Anderson did not indicate how she would change the school in order to accommodate diversity and the educational needs of all students. Bolman and Deal (2013) inform us that when members of the organization fit within human resource frame of the organization, there is harmony, productivity, and usually successful completion of goals. In North Albion, the school as an organization is not compatible with immigrant students and their families. Therefore, to create a more positive fit between the school and the immigrant students, Anderson ought to begin a conversation on changing school structures in order to address the educational needs of ethnically and linguistically diverse students.

Furthermore, research consistently suggests that, in schools that effectively educate ethnically diverse students, the school leaders lead with caring and foster a climate of caring. In other words, it is imperative to lead with an "ethics of caring" and to promote an environment embedded in social justice and a democratic learning community within the schools (Furman, 2000). All three of the school principals showed an understanding of the struggles that the Somali immigrant students are going through; and they are striving to improve the school climate. But, even with a healthy school climate, because of the language barrier, immigrant students might find it difficult to fit in and might feel isolated from the other students. As such, the school principals did not emphasize how they would ensure an empathetic school environment that nurtures immigrant students.

To create culturally inclusive schools, the literature suggests that schools must transform the curriculum into what Ladson-Billings (1994) calls "culturally relevant." Ladson-Billings recommends that educators and teachers adopt and implement culturally relevant knowledge and teaching. According to Ladson-Billings, culturally relevant knowledge is the notion of recognizing the significance and respecting the knowledge that students from different cultural backgrounds bring into the classroom. In addition, culturally relevant teaching also focuses on the teacher facilitating knowledge sharing, preparing students to be critical thinkers, and thereby supporting them to identify the relationships among "community, state and globe" (p. 49). Even though the school principals - both Anderson and Smith - showed an awareness of the hegemonic curriculum that represents the values of the dominant Caucasian middle-class groups in society, they did not mention ways they could make the curriculum more inclusive of the immigrant students' diverse cultures. For instance, none of the schools principals reported 
whether they plan to adopt reading literature that represents the Somali, Hmong and Latino/a students' cultural backgrounds.

With respect to the Hadrawi charter school, when asked about cultural inclusiveness, Baldwin said that diversity is not an issue because the majority of the students (80\%) are Somalis; the other $20 \%$ are Middle Eastern and Oromo. Neither did Baldwin indicate any attempts to connect the curriculum to students' culture; nor did he mention any plans to attract a more ethnically diverse student population to the school. Still, Baldwin stated that the Somali parents have the school they desire. We are somewhat optimistically cautious about the notion of a school that is exclusive to the Somali community. In other words, the Somali students need to be educated in an ethnically diverse school setting that represents the multicultural setting where individualized student growth can be promoted in diverse classrooms that house multi-ethnic students. Otherwise, a majority Somali school could lead to a situation where the Somali students are ghettoized and not able to integrate into the greater society.

However, the Somali parents may have been motivated to create their own charter school by the fear that their children would adapt to undesired elements of western culture that are contrary to Islamic values, such as engaging in pre-marital sex and drinking alcohol. Somali parents desire their children to be educated and integrated into American society without compromising their Islamic identity. This is because the Somali parents regard formal education as an opportunity to obtain and expand the mastery of "instrumental culture" which comprises skills, competencies and social behaviors that are required to successfully make a living and contribute to society (Alitolppa-Niitamo, 2002, p. 280). We believe that, while the children are attending public school, the parents could still instill their Islamic values at home, and at the same time, raise modest Muslim children that attend the public school.

Gardiner and Enomoto (2006) suggest that, when dealing with ethnically and linguistically diverse school populations, school leaders should engage in transformative work by advocating for marginalized families and providing programs such as ESL classes, day care and hiring parents as cafeteria workers or teacher aides. Such support programs somewhat improve the social and economic conditions of the families and, at the same time, enhance the school/family partnership. Anderson indicated that her school does not have a strong partnership with the Somali families, apart from having conferences in the area where the families are concentrated and having interpreters communicate with the parents when issues arise. Holding parent/teacher conferences at the parents' location is a first step, but this does not constitute real partnership.

Smith and Baldwin, on the other hand, provide certain programs for the parents such as ESL classes; they have also hired the parents and members of the community to work in the schools. Baldwin indicated that his school has $100 \%$ parental involvement. He eluded that the reason was that the school itself was created by Somali parents and community members. In other words, partnership with the parents is not an issue. The parents are empowered in the sense that they are the ones who have created the school and, therefore, have a voice in how the school is administered, because most $(60 \%)$ of the board members are Somali parents. Thus, the parents are able to promote their values and interests through the organizational system. 


\section{Recommendations and conclusions}

Meeting the educational needs of all students and creating culturally inclusive schools requires that the school principals first reexamine the schools' visions and address the question of whether the schools' visions represent the educational aspirations of low socioeconomic, immigrant and other minority families. We believe that school visions that were created decades ago no longer represent the values of ethnically and linguistically diverse school communities. Therefore, maintaining and implementing such visions would continue to perpetuate more inequality for minority and immigrant students. Second, building a vision that represents the values of the entire community requires that the principals (Anderson and Smith) promote dialogical relations between ethnically and linguistically diverse communities, including the immigrants and other marginalized groups. Third, the school leaders ought to harness support from the school boards, districts and the communities.

Furthermore, in order for the school principals to turn the schools into learning communities that are culturally inclusive, it is essential to build relationships and trust among the teachers, students and families - including immigrant parents. Shields and Edwards (2005) suggest the use of a carnival as a "catalyst" to "recreate and rejuvenate dialogue" (p. 141). In addition, they indicate that dialogue can be used not only to build relationships but also to diminish certain organizational factors that perpetuate inequities and hinder a healthy learning community. Therefore, it is imperative that the school principals create nonacademic activities that could provide the opportunities for immigrant families and the teachers to get to know each other on a personal level. Eventually, an approach that involves relationship building could assist the school principals' efforts to create more inclusive school cultures that sustain partnerships with the immigrant families.

With respect to connecting the curriculum to the students' cultures - to create a sense of belonging for the immigrant students and to engage them in learning, the school principals would have to create "personal linkages" to the students' diverse cultures by connecting the curriculum to the students' needs. For instance, school principals and teachers could adopt books for reading that represent and affirm the immigrant students' cultures (Katz, 1999; Hertzberg, 1998). Certainly, such books may have positive influence on students' self-worth and identity.

In addition, to create academically responsive classrooms that are also culturally inclusive would require the school principals to differentiate professional development for teachers (Tomlinson \& Allan, 2000) and would also align professional development with the needs of the immigrant students (Feinberg, 2000). For instance, Principals Anderson and Smith talked about educating teachers about the poverty and needs of immigrant students. But there was no indication of aligning professional development with the needs of the immigrant students. Nor did Anderson and Smith discuss adopting professional development that is geared toward educating teachers about refugees and immigrants (some of whom grew up in refugee camps).

To create a genuine school and immigrant family partnership, research recommends that school principals attend to the needs of the parents by providing English language classes, offering full time day-care, creating a site for parents at the school and hiring parents as teacher aides (Gardiner \& Enomoto, 2006; Gitlin et al., 2003). Providing such services not only enhance the school/family partnership but also contribute to the advancement of social justice.

The literature shows that certain schools have established programs that made a difference in educating immigrant students. Such school programs concentrated on addressing the psychological, social and academic needs of immigrant students (Feinberg, 2000). Apart 
from providing ESL and other core subjects, the school principals in this study did not report creating specific programs that dealt with students' psychological needs. Also, the three schools do not have partnerships with social service agencies that could provide counseling to children who have witnessed violence and the trauma of war. For instance, Anderson indicated that her school does not have the capacity to provide counseling to Somali and Hmong students. It is vital to work with other agencies and social services in order to provide counseling to those children. Immigrant and refugee children-specifically those that witnessed violence - need more than ESL and Somali language classes.

Certainly, the principals need to take a more activist role in order to attend to the academic and the psychological needs of the children. This is not an easy task, but it is one that is necessary if the children are to adjust well to school and succeed. This would also require that the school principals communicate to the parents the importance of counseling for some of the children who have witnessed the civil war in Somalia. Somali culture regards anyone who attends counseling as mentally ill; there is stigma attached to seeking psychological treatment or counseling. Therefore, the school principals must work with community leaders and explain to the parents the importance of seeking counseling for children in need of psychological services. As we have indicated elsewhere in this paper, research shows that immigrant/refugee children who have witnessed violence tend to have behavior problems and to engage in fights at school. Therefore, if the Somali refugee/immigrant students are to be adequately educated, addressing only language proficiency is not enough. There has to be a holistic approach to addressing the needs of Somali and other immigrant students. There are those who contend school principals should focus on instructional supervision and make sure the curriculum is delivered accordingly. I believe that adequately ensuring successful student learning and teaching first requires an understanding of the factors that influence student learning. Without addressing those factors, it would be unlikely for students to be able to act normally and focus on learning.

As the principals discussed how they are addressing students' English language acquisition, they did not report utilizing other resources that are available from the University of Minnesota. For instance, it is important to consider building partnerships with the University of Minnesota, which houses America Reads/Counts program that provides undergraduate students as tutors to local schools. In their attempts to improve literacy and English proficiency, the America Reads/Counts program could be beneficial to Somali and other ESL students (McDaniel, 2002).

In addition, given that the school principals indicated that the Somali parents are struggling to adjust and raise children since some of them work two jobs and also face a language barrier, it is challenging for parents also to help support and improve the literacy of their children. Therefore, it would be beneficial if the school principals were to create and provide summer reading programs for the Somali immigrant students. Kim (2006) studied the effects of a voluntary summer reading intervention on reading performance. He carried out a pretest-posttest, control-group experimental design study that measured the effects of voluntary summer reading intervention on fourth-grade students during the summer. The study was a randomized field trial which involved a sample of 552 students in 10 schools in the Lake County school district. Fourth-grade students received eight books to read at home with their parents or family members. After the summer, standardized tests were carried out to measure whether voluntary reading during the summer increased or improved lower-performing students' performance in reading. The findings of the study show that voluntary summer reading could be 
a viable option for improving performance in reading for low-performing students, particularly minority students. For instance, the treatment effects on a standardized test of reading achievement (Iowa Test of Basic Skills) show that the effect size was largest for African American students $(\mathrm{ES}=.22)$ and Latino students $(\mathrm{ES}=.14)$. The study shows that summer reading programs could be employed to increase the reading performance of minority and lowincome students. Hence, we suggest that if the schools promote reading programs during the summer, such programs would also be beneficial to immigrant students who might not have the support to read at home during the summer.

The literature reviewed shows that there are key areas for further research. On one level, limited empirical research exists on the role of school principals in addressing the educational needs of Somali immigrants; therefore, there is a need for further research on this topic.

Even though this study offers an introduction on school leaders' approaches to addressing the educational needs of Somali immigrant and refugee students, the main limitation of the study is that it does not show the perspectives of Somali families' and students' experiences in the schools. Further research needs to be done on how the principals might foster culturally inclusive schools that create nurturing school environments.

This exploratory study has demonstrated the approach of three school principals to addressing the educational needs of Somali immigrant students. The three school principals interviewed for this study are all focused on addressing the essential needs of Somali refugee and immigrant students. As discussed in the previous section, the three school principals are focused on, first, improving the English language proficiency for the students. Second, they provided educational assistants as interpreters to the classroom and to the parents. Third, apart from the Hadrawi School, in order to build partnerships with the Somali families, Smith and Anderson had to overcome cultural and communication barriers that existed between the school and the families. Thus, they all suggested that the key to overcoming challenges involves understanding the culture and experiences of the families and utilizing the expertise of community members in order to bridge the cultural gap.

Even though all three principals demonstrated an understanding of the challenges Somali immigrant students and families are facing, their approaches to addressing the needs of the immigrant students were somewhat similar. For instance, all three principals indicated that they focused on closing the achievement gap and improving English language proficiency for the Somali immigrant students. Nevertheless, it is also important that the approach should not be one that seeks to assimilate the children but rather promotes a multicultural approach that values students' cultures. Smith demonstrated such a multicultural perspective to her responses in addressing the needs of the students. While immigrant students are integrated effectively into her school, she played a role in helping the immigrants preserve their culture by providing Somali language classes to the students.

Two of the school principals, Baldwin and Anderson, maintained the status quo. For instance, Baldwin appeared to be a school manager who performed the tasks that the Somali and East African community assigned him to do-which is to run the school. But he did not indicate his aspirations and plans for diversifying the student body and the teachers. In other words, he did not convey where he would like the school to be. Anderson's approach showed the deficit thinking that her focus was to correct student deficiencies and socialize the Somali students into the American way of life. We also believe that Anderson, as a school leader, has the power to build a more culturally inclusive and socially just school. Quantz, Rogers, and Dantly (1991) contend: "Democracy is not about abandoning power but about using power to promote 
particular relationships" (p. 103). This involves using power to transform present social relations in order to build "better schools" (p. 103). Moreover, Quantz et al. assert that when transformative leaders challenge existing undemocratic relationships or power structures, the dominant groups will "resist and retaliate" (p. 103). Thus, transformative leaders would have to invest in educating the dominant groups about the real meaning of democracy and the collective interest of the entire community.

To address the educational needs of immigrant and other minority students, it is the responsibility of the school leaders to educate the community and facilitate discussions on diversity and equity. This is not a lofty goal, but it is a must if they are to provide adequate education that meets the educational needs of each and every child. As such, Anderson and also Smith would have to facilitate dialogue with all the members of the community and clarify for the teachers and the middle-class families that (a) the school community is changing and (b) educating immigrant students would require redefining the school vision and restructuring the school organization and curriculum. The latter must be done so that a more inclusive school that attends to the educational needs of all of the students is established.

Even though the sample of this study was small, the study shows that in the initial contact with Somali students, the school principals had very little awareness and experience in dealing with Somali refugee and immigrant students who continue to face challenges in adjusting into their schools. To address the educational needs of Somali students requires an approach that transcends the provision of ESL classes. It requires a leadership approach that advocates for the needs of both the students and the parents and seeks to establish certain programs such as reading and mentoring which could play a role in better meeting the educational needs of all students.

To transform schools into democratic organizations requires school leadership that has a higher calling: a leadership that is deeply committed to bringing different cultural groups together in order to build positive relationships and bridge the gap between different ethnic groups in the school and the community. Likewise, to promote democratic schools that embrace the values of diversity would require the school leadership to ask key questions such as whether students of diverse backgrounds (ethnicities, languages and socioeconomic statuses) are provided adequate education that is culturally relevant and at the same time meets the educational needs of each and every child.

In conclusion, the school principals interviewed for this study understand the everpersisting challenges involved in educating multiethnic students, including Somali immigrant students. They all have begun to understand and are empathetic to the challenges the children and their families are going through; and they have some strategies to meet the needs of Somali immigrant students. But at same time, it is vital to seek to increase the transformative work that transcends the technical bureaucratic leadership that could become an obstacle to creating more culturally inclusive schools. To successfully meet the needs of Somali immigrant students, the school leaders need to be the "agents of change" that are committed to the advancement of the values of social justice. This would involve "unpacking" previous approaches and taking a more activist approach to educating immigrant students. Also, this would also involve empowering or helping immigrant parents and community members tap into their energies in order to allow a stronger collective approach to educating the students. Addressing this need will require empowering the Somali immigrant parents and other low socio-economic families so that the community and parents' expertise are harnessed to create a strong school and family partnership. 


\section{References}

Alitolppa-Niitamo, A. (2002). The generation in-between: Somali youth and schooling in metropolitan Helsinki. International Education, 13(3), 275-290.

Bateman, P. (1993). New land, new knowledge: An evaluation of two education programs serving refugee and immigrant students. Retrieved from http://www.eric.ed.gov/ERICWebPortal/search/detailmini.jsp?_nfpb=true\&_\&ERICExtS earch_SearchValue_0=ED364626\&ERICExtSearch_SearchType_0=no\&accno=ED3646 26 (ED 364 626)

Bender, B., \& Murphy, S. (2009, March 12). Security officials warn of Somali recruiting. The Boston Globe. Retrieved from http://www.boston.com/news/nation/washington/articles/2009/03/12/security_officials_w arn_of_somali_recruiting/?page=2

Berg, B. L. (2004). Qualitative research methods for the social sciences. (5th ed.). Boston: Pearson

Bolman, L. G., \& Deal, T. E. (2013). Reframing organizations: Artistry, choice, and leadership. (5th edition). San Francisco: Jossey-Bass.

Coady, M., Hamann, E. T., Harrington, M. P., Pacheco, M., Pho, S., \& Yedlin, J.(2008). Successful schooling for ELLs: Principles for building responsive learning environment. In L. Verplaetse, \& N. Migliacci (Eds.), Inclusive pedagogy for English language learners (pp. 245-55). New York, NY: Taylor and Francis Group.

Darboe, K. (2003). New immigrants in Minnesota: The Somali immigration and assimilation. Journal of Developing Societies, 19(4), 458-472.

Dwyer, M. (1998).Creating change for immigrant learners in secondary schools. TESOL Journal, 7(4), 6-10.

Farid, M., \& McMahan, D. (2004). Accommodating and educating Somali students in Minnesota schools: A handbook for teachers and administrators. Hamline University Press.

Feinberg, R. C. (2000). Newcomer schools: Salvation or segregated oblivion for Immigrant students? Theory into Practice, 39 (4), 220-227.

Forman, M. (2001). Straight outta Mogadishu: Prescribed identities and performative practices among Somali youth in North American high schools. Topia, 5, 33-60.

Furman, G. C., \& Shields, C. M. (2005). How can educational leaders promote and support social justice and democracy community in schools? In W. A. F. C. Riehl (Ed.), A new agenda for research in educational leadership. (pp. 119-137). New York: Teachers College Press.

Gardiner, M. E., \& Enomoto, E. K. (2006). Urban school principals and their roles as multicultural leaders. Urban Education, 41(6), 560-584.

Gitlin, A., Buendia, E., Crosland, K., \& Doumbia, F. (2003). The production of margin and center: Welcoming-unwelcoming of immigrant students. American Educational Research Journal, 40 (1), 91-122.

Harklau, L. (2008). Through and beyond high school: Academic challenges and opportunities for 
college-bound immigrant youth. In S. L.Verplaetse, \& N. Migliacci (Eds.), Inclusive pedagogy for English language learners (pp. 181-194). New York, NY: Taylor and Francis Group.

Hertzberg, M. (1998). Having arrived: Dimensions of educational success in a transitional newcomer school. Anthropology \& Education Quarterly, 29(4), 391-418.

Katz, A. (1999). Keepin'it real: Personalizing school experience for diverse learners to create harmony and minimize interethnic conflict. The Journal of Negro Education, 68(4), 496510.

Kim, J. S. (2006). Effects of voluntary summer reading intervention on reading achievement: Results for randomized field trail. Educational Evaluation and Policy Analysis, 28(4), 335-355.

Ladson-Billings, G. (1994). The Dream keepers: Successful teachers of African American children. San Francisco: Jossey-Bass.

Machel, G. (2001). The impact of war on children. London: Hurst \& Company.

McBrien, J. L. (2005). Educational needs and barriers for refugee students in the United States: A review of the literature. Review of Educational Research, 75(3), 329-64.

McDaniel, C. (2002). Successful implementation of the America reads program: A case study of an effective partnership. Reading Improvement, 39 (4), 175-185.

Perkins, M. L. (2000). The new immigrant and education: Challenges and issues. Educational Horizons, 78(2), 67-71.

Portes, A. \& Zhou, M. (1993). The new second generation: Segmented assimilation and its variants. Annals of the American Academy of Political and Social Science, 530, 74-96.

Quantz, R. A., Rogers, J., \& Dantly, M. (1991). Rethinking transformative leadership: Toward democratic reforms of schools. Journal of Education, 173(3), 96-118

Riehl, C. J. (2000). The principal's role in creating inclusive schools for diverse students: A review of normative, empirical, and critical literature on the practice of educational administration. Review of Educational Research, 70(1), 55-81.

Rutter, J. (2001). Supporting refugee children in $21^{\text {st }}$ century Britain. Stoke on Trent, UK: Trentham Books.

Schaid, J., \& Grossman, Z. (2003). Somali immigrant settlement in small midwestern US communities: The care of Barron, Wisconsin. Eau Claire: University of Wisconsin.

Schultz, R., \& Hertz, D. (2006). Navigating through high school. Principal Leadership, 6(6), 2932.

Shields, C. M. (2003). Good intentions are not enough: Transformative leadership for communities of difference. Lanham, MA: Scarecrow Press.

Shields, C. M., \& Edwards, M. M. (2005). Dialogue is not just talk: A new ground for educational leadership. New York: Peter Lang.

Skrla, L., Scheurich, J.J., Garcia, J., \& Nolly, G. (2004). Equity audits: A practical leadership tool for developing equitable and excellent schools. Educational Administration Quarterly, 40, 133-161.

Tomlinson, C. A., \& Allan, S. D. (2000). Leadership for differentiating schools and classrooms. Alexandria, Virginia: Association for Supervision and Curriculum Development.

Walqui, A. (2008). The development of teacher expertise to work with adolescent English learners. In S. L. Verplaetse, \& N. Migliacci (Eds.), Inclusive pedagogy for English language learners (pp. 103-125). New York, NY: Taylor and Francis Group. 
Yuen, L. (2009, May 29). Young Somali men escape homeland, but not violence. Minnesota Public Radio. Retrieved from http://minnesota. publicradio. org/display/web/2009/05/29/ Somali_youthviolence/

Zehr, M. A., (2001) Out of Africa. Education Week, 20 (27), 30-36.

Zhou, Min (1997). Immigrant adaptation and native-born responses in the making of Americans. International Migration Review, 31(4), 975-1008. 